\title{
The Challenge of Measuring Caries Disease in Populations
}

\author{
Ana Luiza Sarno Castro*1, Maria Isabel Pereira Vianna², Carlos Maurício Cardeal Mendes ${ }^{3}$ \\ ${ }^{1}$ Department of Health, State University of Feira de Santana, Transnordestina, s/n, Novo Horizonte, CEP 44036-900, Feira de Santana, Bahia, Brazil \\ ${ }^{2}$ Department of Public Oral Health, School of Dentistry, Federal University of Bahia, Araújo Pinho, 62, Canela, Salvador, Bahia, Brazil \\ ${ }^{3}$ Postgraduate Studies in Interactive Processes of Organs and Systems, Health Science Institute, Federal University of Bahia, Avenida Reitor Miguel \\ Calmon, 1272, Salvador, Bahia, Brazil
}

${ }^{\star}$ Correspondence author: Ana Luiza Sarno Castro, Department of Health, State University of Feira de Santana, Transnordestina, s/n, Novo Horizonte, CEP 44036-900, Feira de Santana, BA, Brazil; E-Mail Id: alscastro@yahoo.com.br

Received: September 19, 2018; Accepted: September 26, 2018; Published: October 14, 2018;

\begin{abstract}
Introduction: There are so many methods for measuring caries disease in populations that it is a great challenge for researchers and epidemiologists to choose which one is most appropriate for their research or surveys.
\end{abstract}

Objective: to make a discussion about the difficulties in measuring caries disease in populations using scientific articles that contributed to the reflection on the subject.

Conclusion: Due to the importance of the issue a careful analysis of the literature is necessary to decide which method should be used to measure caries disease in the populations.

Keywords: DMF index, caries dental; health surveys.

Caries is a chronic disease worldwide and, according to the World Health Organization (WHO), affects $60-90 \%$ of school-age children and $100 \%$ of adults in various regions [1], with considerable variations between countries. In 2010, untreated caries lesions on permanent teeth were the most prevalent condition worldwide, affecting 2.4 billion people, with potential impact on the global economy [2]. Despite the importance of this disease, there is no consensus as to the most appropriate method for the detection of caries in populations, so there are numerous methods described in the literature [3-10]. Due to many options that currently exist researchers and epidemiologists need to be aware of several aspects when choosing a method to detect caries in populations. Before choosing a method, it is recommended that the researcher analyze several questions to determine which method is most appropriate to the objectives of his research or his epidemiological survey. These questions will be addressed here, while a comparison will be made between three methods that stood out in the literature, being validated and used internationally [11-13]: The Caries Assessment Spectrum and Treatment (CAST) [14], the International Caries Detection and Assessment System (ICDAS) [8] and the DMF (Decayed, Missing and Filled) [15].

The first question is:- What diagnostic threshold will be used to detect caries lesions? This threshold can vary from enamel lesions visualized after we dried the enamel until extensive dentin lesions have reached the pulp and caused an odontogenic infection. DMF has traditionally measured caries from dentin lesions (D3), leaving lesions in enamel (D1) sub registered. The CAST measures from noncavitary enamel lesions that do not need to be dried to be detected, not using compressed air. The ICDAS measures from the first clinical sign of caries that are non-cavitated enamel lesions that need to be dried for 5 seconds to be seen [16]. The CAST and the ICDAS decrease the underestimation of caries when diagnosing these diseases from enamel lesions.

The second question is:- Which unit of measurement we will use? Can the individual unit be chosen when we detect how many individuals are sick in a community, for example, in 100 individuals who have lesions of caries? When we use teeth unit in a group of 100 people how many of its 3200 teeth have been affected? We can use the surface unit and, if so, how many of the 1,4800 surfaces examined have been affected by caries? In each one, caries can reach different levels of severity, from a reversible enamel lesion to total surface/tooth destruction.

A third important question relates to the choice of unit of measure we will include in calculating the prevalence of caries disease. The number of people with caries lesions? Alternatively, the number of teeth or surfaces affected by caries? [15]

With DMF and ICDAS the tooth or surface unit has been used. However, this makes it difficult to communicate with other areas of health and with planners and decision-makers, since generally the prevalence is calculated using the individual unit of measure. The 
prevalence of a disease is the proportion of a population that has a disease at a specific level at a point in time [17]. In epidemiology, a patient has one or more diseases, while the rest of the population is healthy. The sick individuals correspond to the number of cases [18].

In Dentistry, however, this principle is generally not followed, and therefore there is a specific approach to the tooth. It means that will be checked whether each tooth is diseased or not, by adding the tooth that has the disease at the time of examination (caries lesions) with the teeth that have been affected by it in the past and have been extracted or restored. However, it may be misleading to consider the teeth restored and absent as experience of caries because the teeth may have been restored or extracted for other reasons [18].

The CAST uses the individual unit to calculate the prevalence of caries without considering the extracted or restored teeth [19], which is more in agreement with the classical concept of prevalence because it detects the disease present at the moment of the examination per individual, thus identifying the individuals who need dental treatment at the time of the examination. When individuals receive this treatment, they are excluded from the disease prevalence this allows communicating more quickly to health planners the results of interventions in a given community.

A fourth and final question is: - We will evaluate the activity of the lesion? That is, once the lesion is detected, we must consider as active or inactive through its appearance?

The usefulness of measuring caries activity is questionable because when some authors $[20,21]$ used this indicator no significant change was identified. These authors argue that treating all non-cavitated lesions, as if they were all with active caries, instead of evaluating the caries activity, would be better cost-effective in the long term. CAST and DMF do not include caries activity. However, ICDAS has been proposed to be used in conjunction with methods that evaluate this activity (Nyvad System [6], Lesion Activity Assessment - LAA [22], and LA from the International Caries Classification and Management System - ICCMS [23] ).

According to Frencken [24], for an epidemiological index, it is not advantageous to include assessment of caries activity, as this would only make the index more complicated. However, for Nyvad [6], the evaluation of the lesion activity is essential for the determination of the need for treatment, since the active lesions require intervention (operative or non-operative), while inactive lesions require only the daily use of fluoride toothpaste.

The registry of non-cavitated enamel lesions aims to provide a more comprehensive epidemiological picture of the distribution of the disease in the population; however, to include these lesions, it is necessary that the teeth be dry, requiring more calibration time for examiners and a more detailed examination [1]. The choice of a particular method should take into account the purpose of the study, the human resources, and the materials available. Epidemiological surveys conducted in underdeveloped or developing countries have scarce resources, and therefore epidemiologists have chosen DMF because it is a quick and inexpensive index.
Limits and deficiencies of DMF have been reported in the literature, some authors point out the need to use new methods that measure caries disease in populations in a way that is more in agreement with new concepts of cariology and epidemiology, including non-cavitated enamel lesions and using an individual unit of measure [18, 25]. Given the importance of measuring caries in populations, studies are needed to assist researchers in the choices among the various methods. Castro et al. [26] compared to CAST, ICDAS, and DMF. After this study the authors arrived at the following conclusions:

\section{Advantages and disadvantages of DMF}

The DMF uses the unit of measure tooth or surface and offers as advantages: ease of use; speed of application; simplicity of analysis; does not require the use of compressed air; is recommended by WHO and MS; is comparable with international data collected since the 1940s. As for disadvantages of DMF, the authors cite: the use of the DMF mean that considers very different clinical conditions, implying the need to decompose the index in the lost and restored caries components, to verify how much each one is present in the population; traditionally, does not include lesions on enamel. The DMF includes decayed, restored and lost teeth, so it is an irreversible index; the prevalence calculated through it will never decrease in the same group over time; therefore, measures the prevalence of the disease cumulatively. That is, individuals who are no longer with the disease at the time of the examination can be included in the prevalence of the disease; also, some teeth may have been extracted or restored for reasons other than caries, overestimating the presence of the disease.

\section{Advantages and disadvantages of ICDAS}

As advantages of the ICDAS, it includes the caries lesions from its most initial clinical stage, when it is only possible to visualize the lesion through surface drying. This system is used in association with other methods that evaluate caries activity (Nyvad System, LAA, LA) $[6,22,23]$.

It is a validated method used in several countries; its data are capable of being transformed into an average DMF; is an appropriate system for clinical use and for monitoring the evolution of individual caries lesions. The disadvantages of the ICDAS are based on the fact that for this method to record enamel lesions, it is necessary to use compressed air to dry each surface for 5 seconds, but in many places, it is not possible to use this equipment. By using many codes and two digits, the analysis becomes complex and overly detailed to be used at the collective level [27].

\section{Advantages and disadvantages of CAST}

The CAST can use the individual, tooth or surface unit measure, has the benefits of detecting enamel lesions that can be visualized without the use of a compressed air syringe, to lesions that caused fistula and abscess. Don't need compressed air; it is a simple, fast method; was validated and used internationally; its criteria are arranged hierarchically, easy to apply and analyze; data can be transformed into an average DMF $[14,26]$.

The cited disadvantages of CAST were: it was not tested for clinic use [28]; does not measure enamel lesions that can only be 
seen after tooth drying. Not including this type of lesion is part of the characteristics that make this method more suitable for use in epidemiological surveys. The lack of knowledge about new methods to measure caries in the populations influences the decision on which index to use, as shown in the study by CASTRO et al. [29] most of the people interviewed said they were dissatisfied with DMF, but they did not use new methods because they could not compare the data later. However, both the CAST and the ICDAS had their data converted to the DMF mean in several studies, with results very similar to those found with the last index [26]. Therefore, the perception that there would be a loss of comparability of results, using other methods, is questionable, since data obtained through the ICDAS and CAST can be converted and compared to data previously registered with the DMF [26].

\section{Conclusions}

Due to the importance of the subject and the number of methods proposed, a careful analysis of the literature is necessary to decide which method should be used to measure caries disease in the populations because all of them have advantages and disadvantages. More studies should be done on the subject until a consensus is established.

\section{Authors' contributions}

ALSC drafted the manuscript; ALSC, CMCM, and MIPV reviewed the original draft as well as read and approved the final manuscript.

\section{References}

1. Antunes JLF, Peres MA, Crivello Júnior O (2006) Epidemiology of oral health. In: Fundamentals of Dentistry. Guanabara Koogan pg: 441-442.

2. Kassebaum NJ, Bernabé E, Dahiya M, Bhandari B, Murray CJ, et al. (2015) Global burden of untreated caries: a systematic review and metaregression. J Dent Res 94 : 650-658. [crossref]

3. Mount GJ, Hume WR (1997) A revised classification of carious lesions by site and size. Quintessence Int 28: 301-303. [crossref]

4. Fisher J, Glick M, Committee FWDFS (2012) A new model for caries classification and management: the FDI World Dental Federation caries matrix. Elsevier pg: $546-551$.

5. de Souza AL, Leal SC, Bronkhorst EM, Frencken JE (2014) Assessing caries status according to the CAST instrument and WHO criterion in epidemiological studies. BMC Oral Health 14: 119. [crossref]

6. Nyvad B (2004) Diagnosis versus detection of caries. Caries Res 38: 192-198. [crossref]

7. Castro ALS, Vianna MIP, Reis SR de A (1999) A new index for measuring dental caries: a reversible index of dental caries-IRCD. Rev Fac Odontol Univ Fed Bahia 19: $35-40$.

8. Ismail AI, Sohn W, Tellez M, Amaya A, Sen A, et al. (2007) The International Caries Detection and Assessment System (ICDAS): an integrated system for measuring dental caries. Community Dent Oral Epidemiol 35: 170-178.

9. Sheiham A, Maizels J, Maizels A (1987) New composite indicators of dental health. Community Dent Health 4: 407-414. [crossref]

10. Monse B, Heinrich-Weltzien R, Benzian H, Holmgren C, van Palenstein Helderman W (2010) PUFA-An index of clinical consequences of untreated dental caries. Community Dent Oral Epidemiol 38: 77-82.

11. de Souza AL, Bronkhorst EM, Creugers NH, Leal SC, Frencken JE (2014) The caries assessment spectrum and treatment (CAST) instrument: its reproducibility in clinical studies. Int Dent J 64: 187-194. [crossref]

12. Frencken JE1, de Souza AL, van der Sanden WJ, Bronkhorst EM, Leal SC (2013) The Caries Assessment and Treatment (CAST) instrument. Community Dent Oral Epidemiol 41: 71-77. [crossref]

13. Braun A, Guiraud LMJC, Frankenberger R (2017) Histological validation of ICDAS II and radiological assessment of occlusal carious lesions in permanent teeth. Odontology 105: 46-53.
14. Frencken JE, de Amorim RG, Faber J, Leal SC (2011) The Caries Assessment Spectrum and Treatment (CAST) index: rational and development. Int Dent $J$ 61: 117-123. [crossref]

15. Klein H, Palmer CE (1938) Dental caries in American Indian children. US Govern. Print Off.

16. Frencken JE (2016) Dental Caries and Caries Epidemiology. In: Evidence-Based Caries Prevention. Springer pg: 1-11.

17. Rothman KJ (1998) Precision and validity in epidemiologic studies. Mod Epidemiol.

18. Larmas M, Mäkinen KK (2014) Insufficiency of currently used dental indices in epidemiology. Br J Med Med Res 4: 2058.

19. Ribeiro APD, Maciel IP, de Souza Hilgert AL, Bronkhorst EM, et al. (2018) Caries assessment spectrum treatment: the severity score. Int Dent J 68: 84-90. [crossref]

20. Brown JP, Amaechi BT, Bader JD, Shugars D, Vollmer WM, et al. (2015) The dynamic behavior of the early dental caries lesion in caries-active adults and implications. Community Dent Oral Epidemiol 43: 208-216.

21. Piovesan C, Ardenghi TM, Guedes RS, Ekstrand KR, Braga MM, et al. (2013) Activity assessment has little impact on caries parameters reduction in epidemiological surveys with preschool children. Community Dent Oral Epidemiol 41: 204-211.

22. Ekstrand KR, Martignon S, Ricketts DJN, Qvist V (2007) Detection and activity assessment of primary coronal caries lesions: a methodologic study. Oper Dent 32 : $225-235$.

23. Pitts NB, Ekstrand KR (2013) International Caries Detection and Assessment System (ICDAS) and its International Caries Classification and Management System (ICCMS)-methods for staging of the caries process and enabling dentists to manage caries. Community Dent Oral Epidemiol 41: 41-52.

24. Frencken JE, de Souza AL, van der Sanden WJ, Bronkhorst EM, Leal SC (2013) The Caries Assessment and Treatment (CAST) instrument. Community Dent Oral Epidemiol 41: e71-77. [crossref]

25. Ismail A1 (2004) Diagnostic levels in dental public health planning. Caries Res 38: 199-203. [crossref]

26. Castro ALS, Vianna MIP, Mendes CMC (2018) Comparison of caries lesion detection methods in epidemiological surveys: CAST, ICDAS and DMF. BMC Oral Health 18: 122.

27. de Amorim RG, Figueiredo MJ, Leal SC, Mulder J, Frencken JE (2012) Caries experience in a child population in a deprived area of Brazil, using ICDAS II. Clin Oral Investig 16: 513-520. [crossref]

28. Leal SC, Ribeiro APD, Frencken JE (2017) Caries Assessment Spectrum and Treatment (CAST): A Novel Epidemiological Instrument. Caries Res 51: 500-506.

29. Castro ALS, Vianna MIP, Mendes CMC (2018) The knowledge and use of population-based methods for caries detection. BMC Oral Health 18: 153. [crossref]

Citation:

Ana Luiza Sarno Castro (2018) The Challenge of Measuring Caries Disease in Populations. J Dent Maxillofacial Res Volume 1(1): 1-3. 